\title{
Pembuatan Stik Pelangi untuk pembelajaran bangun datar dan warna pada TK Pertiwi Bungu Kecamatan Mayong Kabupaten Jepara
}

\author{
${ }^{1}$ Eka Setya Budi*, ${ }^{1}$ Alex Yusron Al Mufti, ${ }^{2}$ Haryanto \\ ${ }^{1}$ Prodi Pendidikan Agama Islam, Fakultas Tarbiyah dan Ilmu Keguruan, UNISNU, Jepara, Indonesia \\ ${ }^{2}$ Prodi Pendidikan Bahasa Inggris, Fakultas Tarbiyah dan Ilmu Keguruan, UNISNU, Jepara, Indonesia \\ *Corresponding Author \\ Jalan Taman Siswa Pekeng Tahunan Jepara Indonesia 59427 Telp. (0291) 592630 \\ Email: ekasetyabudi35@gmail.com
}

$\begin{array}{llll}\text { Received: } & \text { Revised: } & \text { Accepted: } & \text { Published: } \\ \text { 16 September 2019 } & \text { 24 October 2019 } & \text { 18 November 2019 } & \text { 30 November 2019 }\end{array}$

\begin{abstract}
Abstrak
Media pembelajaran yang tepat, sangat mendukung keberhasilan pembelajaran baik dari segi kualitas maupun kuantitas. Oleh karenanya, pemilihan dan penggunaan media pembelajaran harus disesuaikan dengan kebutuhan dan kesesuaian materi. Mengenalkan pesrta didik bentuk bangun datar dan warna kebanyakan menggunakan gambar atau alat peraga dalam jumlah banyak. Hal ini menjadikan pengajaran di sekolah terkesan ribet, guru terkesan kurang kreatif dan inovatif dalam proses pembelajaran di TK Pertiwi desa Bungu. Solusi yang ditawarkan pada program pengabdian kepada masyarakat ini adalah pembuatan "stik pelangi" bagi guru TK Pertiwi Desa Bungu sebagai media pembelajaran bangun datar dan warna. ini diharapkan akan membentuk komunikasi pembelajaran yang efektif di antara guru dan peserta didik, karena proses pembelajaran akan lebih menarik dan mengesankan. Permasalahan yang dihadapi mitra TK Pertiwi Desa Bungu yaitu (1) hasil pembelajaran materi bangun datar dan warna belum optimal. (2) guru TK Pertiwi Desa Bungu belum profesional dalam membuat media pembelajaran. Stik Pelangia dalah program membuat media pembelajaran yang simple kreatif dan inovatif serta tidak membutukan biaya yang signifikan. Media ini dirancang dengan sedemikian rupa agar tujuan pembelajara dapat tercapai. Dengan adanya pembuatan "Stik pelangi" bagi guru TK Pertiwi Desa Bungu hasil pembelajaran materi bangun datar dan warna peserta didik dapat tercapai secara maksimal.
\end{abstract}

Keywords: Stik pelangi; bangun datar; TK Pertiwi Bungu

\begin{abstract}
Appropriate learning media greatly support the success of learning both in terms of quality and quantity. Therefore, the selection and use of learning media must be adjusted to the needs and suitability of the material. Introducing students form flat shapes and colors mostly using pictures or props in large quantities. This makes teaching in schools seem complicated, teachers seem less creative and innovative
\end{abstract}


in the learning process in Pertiwi Kindergarten in the village of Bungu. The solution offered in this community service program is the creation of a "rainbow stick" for the Pertiwi TK Kindergarten teacher as a medium of learning to build flat and color. This is expected to form effective learning communication between teachers and students, because the learning process will be more interesting and impressive. The problems faced by TK Pertiwi Kindergarten partner are (1) the learning outcomes of flat and color material are not optimal. (2) TK Pertiwi kindergarten teacher is not yet professional in making learning media. RainbowStick is a program that makes learning media that is simple, creative and innovative and does not require significant costs. This media is designed so that learning objectives can be achieved. With the creation of "Rainbow Sticks" for kindergarten teachers in Pertiwi Bungu Village, the learning outcomes of the material in the shape of the flat and the colors of students can be achieved optimally.

Keywords: Rainbow Stick, two-dimentional figure, TK Pertiwi Bungu

\section{PENDAHULUAN}

\section{Analisis Situasi}

TK Pertiwi Desa Bungu adalah TK yang termasuk daerah binaan Ikatan Guru Taman Kanakkanak Kecamatan Mayong. TK pertiwi Desa Bungu berjarak kurang lebih $15 \mathrm{KM}$ dari pusat kota. TK ini berdiri pada tahun 2008 dan beroperasi hingga sekarang yaitu tahun 2018. TK Pertiwi Desa Bungu dipimpin oleh Lailatul Mutmainah, S.Pd. TK ini memiliki permasalahan tentang model pembelajaran pendidikan karakter (Zuchdi dkk., 2009; Koesoema A., 2007). Di TK Pertiwi Desa Bungu guru mendaptkan kesulitan dalam menggunakan model, teknik, dan pendekatan termasuk apa saja yang dapat meningkatkan hasil belajar peserta didik (Sumiati \& Asra, 2009; 2017:42; Senjaya, 2008:127; Winataputra, 2003:126) pada materi bangun datar dan warna.

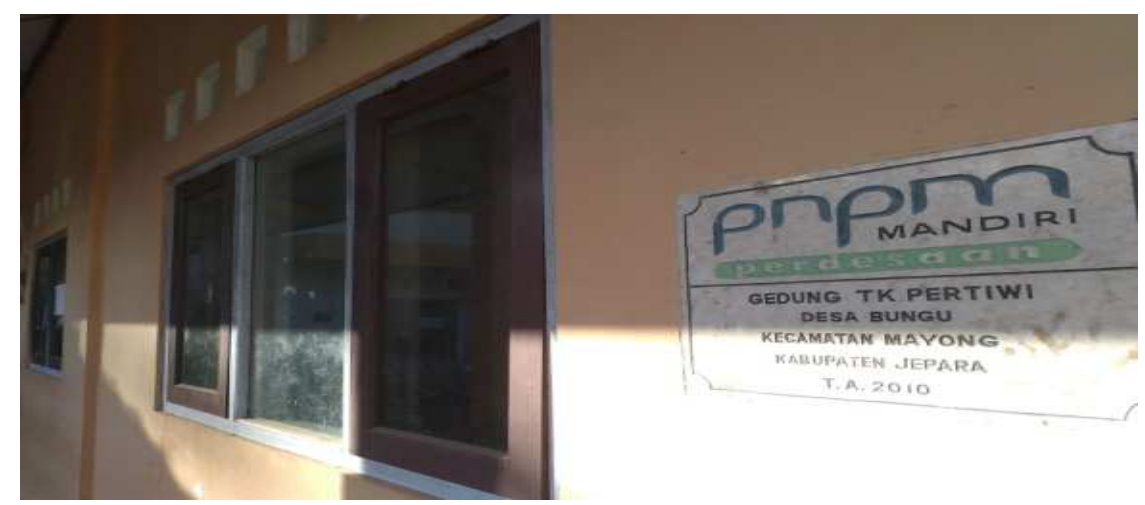

Gambar 1. Deskripsi gedung TK Pertiwi Desa Bungu

Berdasarkan hasil observasi yang telah observer lakukan di TK Pertiwi Desa Bungu. Model pembelajaran pada materi bangun datar dan warna belum menampakkan hasil yang optimal. Di Tk Pertiwi Desa Bungu selama ini guru dalam materi bangun datar dan warna 
peserta didik di taman kanak-kanak hanya mengajarkan secara teoretis saja. Peserta didik mengetahui apa itu segi empat, segi tiga, jajaran genjang, dan bangun datar lainnya dalam praktiknya peserta didik tidak mencerminkan sikap serius (Campagne. (2007)..Seharusnya guru di TK Pertiwi Desa Bungu dalam mengajar perlu mempraktikan kedalam wujud yang konkret, agar anak mampu mengatasi konflik dalam kehidupan sosial di masa dewasa kelak (Marilyne \& Sue, 2009: Brewer 2007:20). Keadaan proses pembelajaran karakter di TK Pertiwi Desa Bungu dapat dijelaskan pada tabel 1.

Tabel 1. Deskripsi proses pembelajaran karakter di TK Pertiwi Desa Bungu

\begin{tabular}{cc}
\hline $\begin{array}{c}\text { Aspek } \\
\text { Pembelajaran }\end{array}$ & \multicolumn{1}{c}{ Uraian Kondisi TK Pertiwi Desa Bungu } \\
\hline Guru & - $\begin{array}{l}\text { Sebagian guru sudah memenuhi kualifikasi sebagai tenaga } \\
\text { pendidik. }\end{array}$ \\
\hline Peserta Didik & - $\begin{array}{l}\text { Hasil belajar pada materi bangun datar dan warna belum } \\
\text { menggembirakan }\end{array}$ \\
& - Peserta didik tidak memiliki motivasi belajar hal ini terlihat \\
& pada saat proses pembelajaran mereka terlihat ogah-ogahan. \\
& - Ada 80\% peserta didik tidak memiliki tanggung jawab \\
& sehingga tidak melaksanakan tugas dan kewajibannya \\
& sebagaimana yang seharusnya dia lakukan, terhadap diri \\
& sendiri, masyarakat, lingkungan (alam, sosial dan budaya), \\
& negara dan Tuhan YME. \\
& Peserta didik tidak memiliki disiplin sehingga peserta didik \\
& tidak tertib dan patuh pada berbagai ketentuan dan peraturan \\
& yang berlaku. \\
& - Sebagian besar peserta didik tidak memiliki kesungguhan atau \\
& kerja keras sehingga tidak memiliki upaya sungguh-sungguh \\
& dalam mengatasi berbagai hambatan guna menyelesaikan tugas \\
& belajar pada materi bangun datar dan warna. \\
\hline Model & Model pembelajaran yang digunakan guru masih konvensional. \\
& - Model pembelajarannya masih bersifat teoretis \\
\hline Alat & - Sarana dan prasarananya masih belum lengkap \\
pembelajaran & Tidak adanya perhatian dari pihak lainnya \\
\hline Evaluasi & \multicolumn{1}{c}{ Sitem evaluasi belum outentik } \\
\hline
\end{tabular}

\section{Permasalahan Mitra TK Pertiwi Desa Bungu}

Permasalahan prioritas yang dihadapi mitra di TK Pertiwi Desa Bungu adalah pada saat proses pembelajaran. Guru belum menemukan formula yang tepat yang digunakan pada proses pembelajaran pada materi bangun datar dan warna. Guru cenderung bersifat pragmatis (pokoke) maksudnya, guru hanya menyampaikan materi secara klasikal atau teoretis saja. Hal ini terjadi baik di TK Pertiwi Desa Bungu. 
Tabel 2. Deskripsi permasalahan mitra pada proses pembelajaran bangun datar

\begin{tabular}{|c|c|}
\hline Aspek & Permasalahan \\
\hline Peserta Didik & $\begin{array}{l}\text { Peserta didik tidak memiliki motivasi belajar pada } \\
\text { materi bangun datar dan warna. } \\
\text { Peserta didik tidak memiliki tanggung jawab sehingga } \\
\text { tidak melaksanakan tugas dan kewajibannya } \\
\text { sebagaimana yang seharusnya dia lakukan, terhadap } \\
\text { diri sendiri dan masyarakat, } \\
\text { Peserta didik tidak memiliki sikap disiplin sehingga } \\
\text { peserta didik tidak tertib dan patuh pada berbagai } \\
\text { ketentuan dan peraturan yang berlaku. } \\
\text { - Pserta didik tidak memiliki kesungguhan atau kerja } \\
\text { keras sehingga tidak memiliki upaya sungguh-sungguh } \\
\text { dalam mengatasi berbagai hambatan guna } \\
\text { menyelesaikan tugas belajar. } \\
\text { Peserta didik tidak memiliki kemandirian,terlihat setiap } \\
\text { ada tugas peserta didik mudah tergantung pada orang } \\
\text { lain dalam menyelesaiannya }\end{array}$ \\
\hline $\begin{array}{r}\text { Model } \\
\text { Pembelajaran }\end{array}$ & $\begin{array}{l}\text { Model pembelajaran yang digunakan guru masih } \\
\text { konvensional dan teoretis saja. }\end{array}$ \\
\hline Alat pembelajars & $\begin{array}{l}\text { - Sarana dan prasarananya masih belum lengkap } \\
\text { - Tidak adanya perhatian dari pihak lainnya }\end{array}$ \\
\hline
\end{tabular}

\section{METODE}

\section{Tahap persiapan}

Tahap persiapan adalah tahap menyiapkan alat dan bahan yang akan digunakan untuk pembuatan stik pelangi. Adapun bahan yang digunakan adalah: gunting, kertas warna, kancing ceplis, dan beberapa alat yang telah dipersiapkan dalam RAB. Tahap persiapan ini juga dipersiapkan agar guru-guru TK Pertiwi Desa Bungu siap mengikuti pembuatan media pembelajaran untuk materi bangun datar dan warna.

\section{Tahap Pelaksanaan}

Proses pengembangan media stik pelangi bertujuan untuk mengenalkan peserta didik pada materi bangun datar dan warna terbagi atas dua tahap. Pada tahap pertama, pengabdi merealisasikan ciri-ciri dan kriteria media yang disusun berdasarkan kecenderungan kebutuhan peserta didik dan guru. Tahap kedua, produk yang telah diujikan merupakan produk hasil evaluasi oleh para penguji ahli.

Gambaran mengenai proses pembuatan media dimulai dari pembuatan 1) analisis kebutuhan konsumen; 2) pembuatan stik pelangi sederhana; dan 3) kemasan pembelajaran yang secara keseluruhan disesuaikan dengan karakteristik media. Penjelasan poin-poin yang mencerminkan urutan langkah-langkah tersebut dijelaskan dalam bagan berikut. 


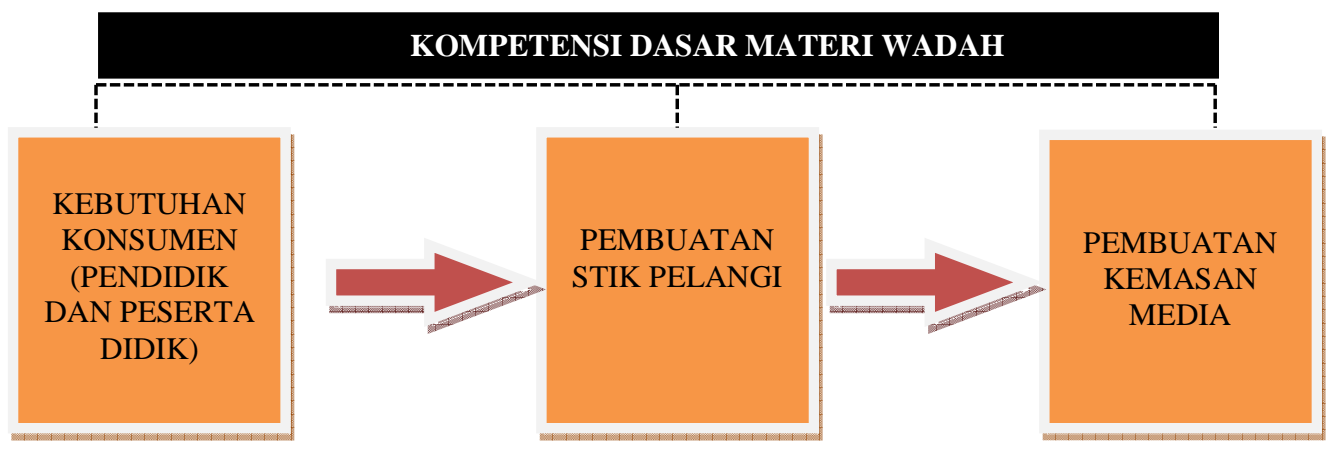

Gambar 2. Bagan alur PKM pembuatan Stik Pelangi

Penjelasan mengenai bagan tersebut diuraikan dalam beberapa tahapan yang telah disampaikan pada bagian 1 sampai dengan 3. Tahapan dijelaskan secara rinci sebagai wujud aktualisasi proses pembuatan media pembelajaran yang telah disesuaikan dengan proses sebenarnya (Sugiyono, 2009). Paparan mengenai alur pembuatan dapat dilihat dalam penjelasan di bawah ini.

1. Kebutuhan Konsumen dalam Media Stik Pelangi untuk mengenalkan peserta didik pada materi bangun datar dan warna pada peserta didik Taman kanak-kanak. Kompetensi dasar mengenal bangun datar dan warna merupakan rujukan utama dalam media pembelajaran yang akan dibuat.

2. Kebutuhan Konsumen dalam Media Stik Pelangi

Proses pembuatan media kipas pintar untuk mengenalkan peserta didik pada materi warna dan bangun datar meninjau materi berdasarkan muatan kompetensi dasar (KD); b) menentukan muatan materi bangun datar dan warna; dan c) membuat skenario media yang mencerminkan realisasi media pembelajaran.

Pada tahap kedua, pengabdi memilih kompetensi dasar (KD) pada peserta didik TK kelas B semester 2 mengenai materi bangun datar dan warna. Indikator mengenai KD ini adalah sebagai berikut (a) mampu menunjukkan warna dan (b) mampu menunjukkan bangun datar.

Pada kelas B di TK juga memuat materi mengenai bangun datar dan warna. Tentu saja, hal ini menjadi aucan dalam penentuan materi yang akan disampaikan dalam proses pembelajaran. Atas hal tersebut, sajian materi yang perlu dirangkai untuk mewujudkan pembelajaran adalah merangkai teori pembelajaran warna, dan bangun datar.

Bentuk stik pelangi terdiri dari 1 bagian untama. Adapun uraiannya dapat dilihat pada deskrepsi berikut.

1. Bentuk Awal untuk Pembelajaran Materi Warna

2. Bentuk Ketiga untuk Pembelajaran Materi Bangun Datar

Wujud bangun datar yang dihasilkan dari Stik Pelangi adalah bangun-bangun sederhana. Bangun datar yang dimaksud adalah bentuk bangun datar yang berwujud segitiga, segi empat, jajaran genjang, belah ketupat, segi lima, segi enam, persegi panjang, dan lingkaran (Suharjana, Agus. 2008; Setiawan, 2000). Untuk dapat mempraktikkan bangun datar yang dimaksud adalah dengan melepas kunci pada kipas pintar yang berada pada bawah, kemudian menyambungkan pada klem yang berada pada atas bentuk Stik Pelangi. Dengan 
menyambungkan antara ruas satu dengan yang lainnya maka kita dapat membuat bangun datar sesuai dengan kehendak kita.

\section{HASIL DAN PEMBAHASAN}

Hasil Kegiatan

Hasil kegiatan PKM dengan implementasi pembuatan stik pelangi pada TK Pertiwi Desa Bungu adalah berupa produk APE (Alat Peraga Edukatif) yang bernama Stik Pengi. Stik Pelangi ini pembuatannya sangat mudah karena hanya memanfaatkan barang-barang bekas dan beberapa alat berupa palu, pisau, dan kancing ceplis.

Tahap pertama pembuatan Stik Pelangi

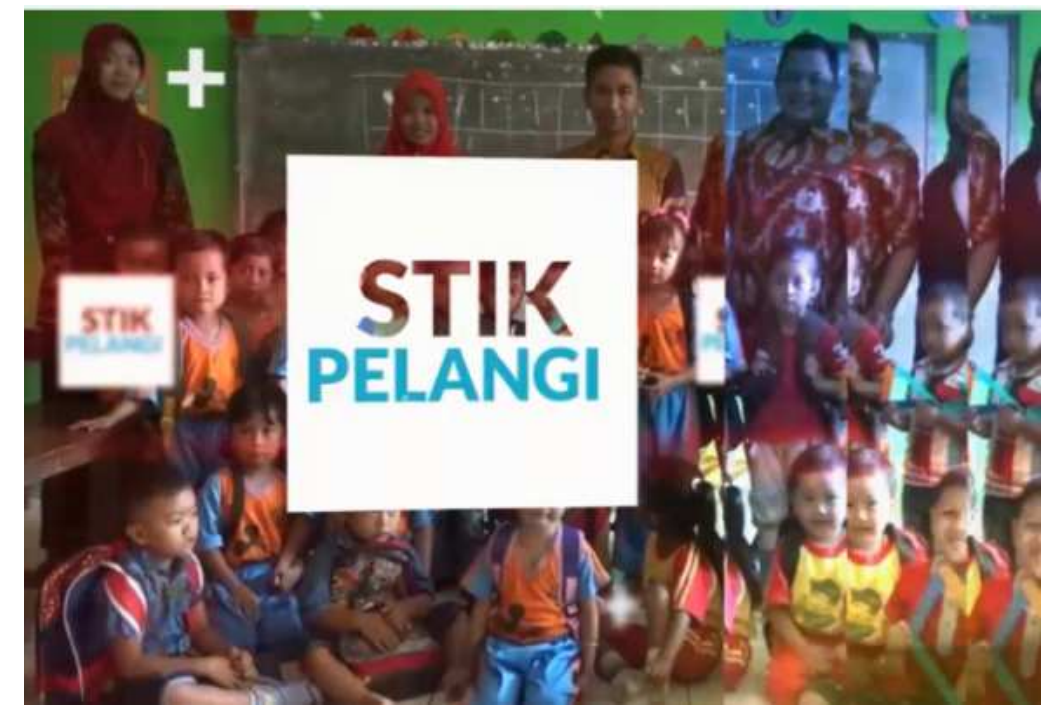

Gambar 3. Opening Stik Pelangi

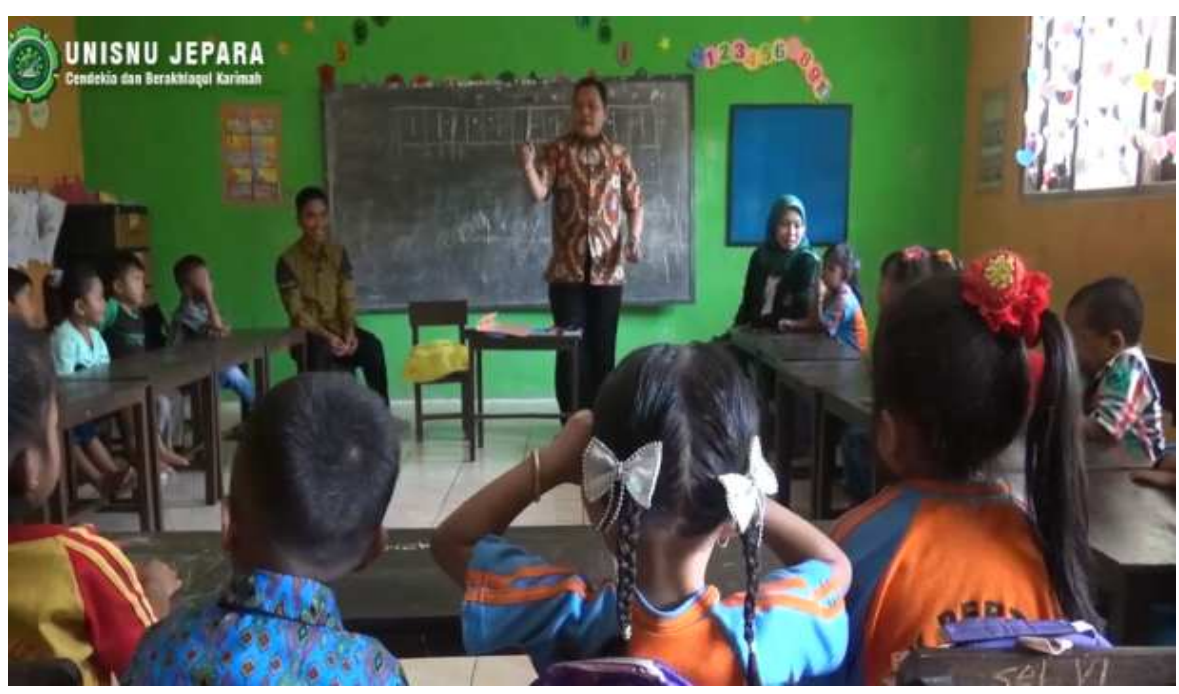

Gambar 4. Bahan Stik Pelangi 
Indonesian Journal of Community Services

Volume 1, No. 2, November 2019

http://jurnal.unissula.ac.id/index.php/ijocs DOI: http://dx.doi.org/10.30659/ijocs.1.2.194-201

Tahap kedua pembuatan Stik Pelangi

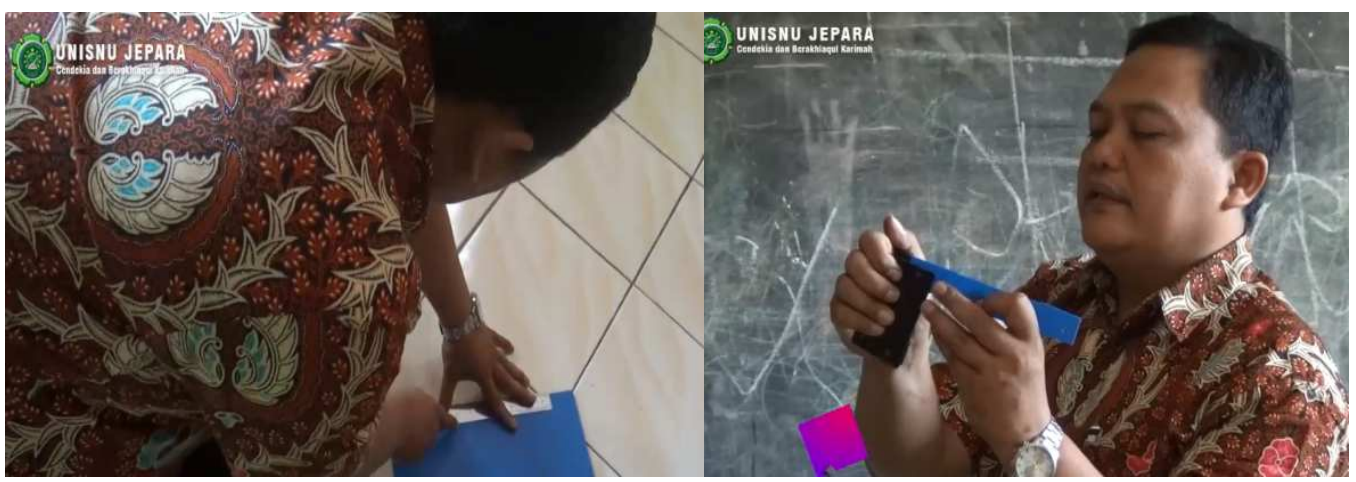

Gambar 5. Langkah Pembuatan Stik Pelangi

Tahap ketiga pembuatan Stik Pelangi

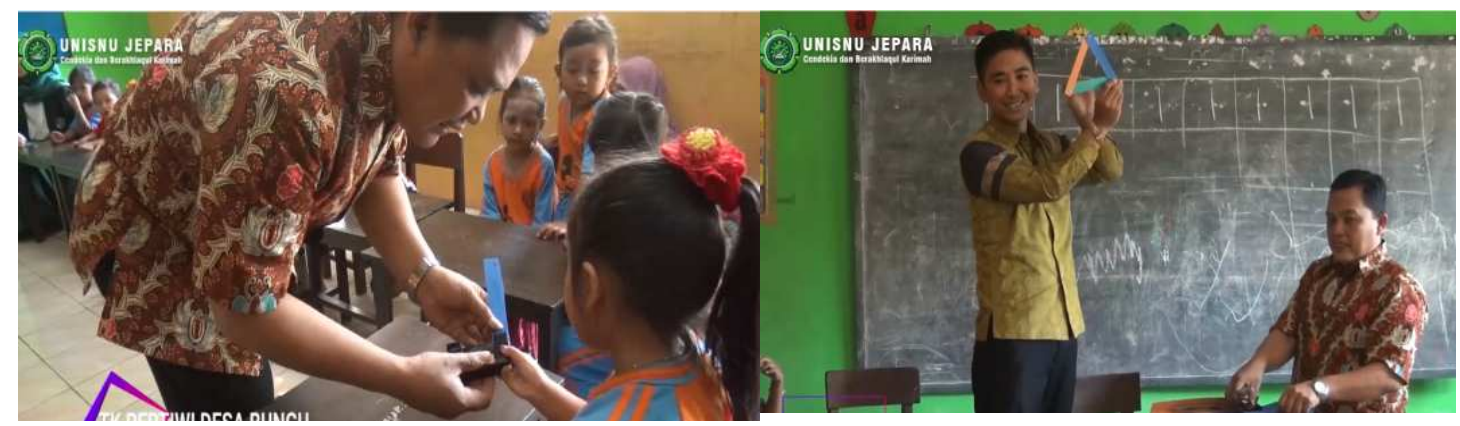

Gambar 6. Pelibatan pembuatan Stik Pelangi

Tahap kempat pembuatan Stik Pelangi

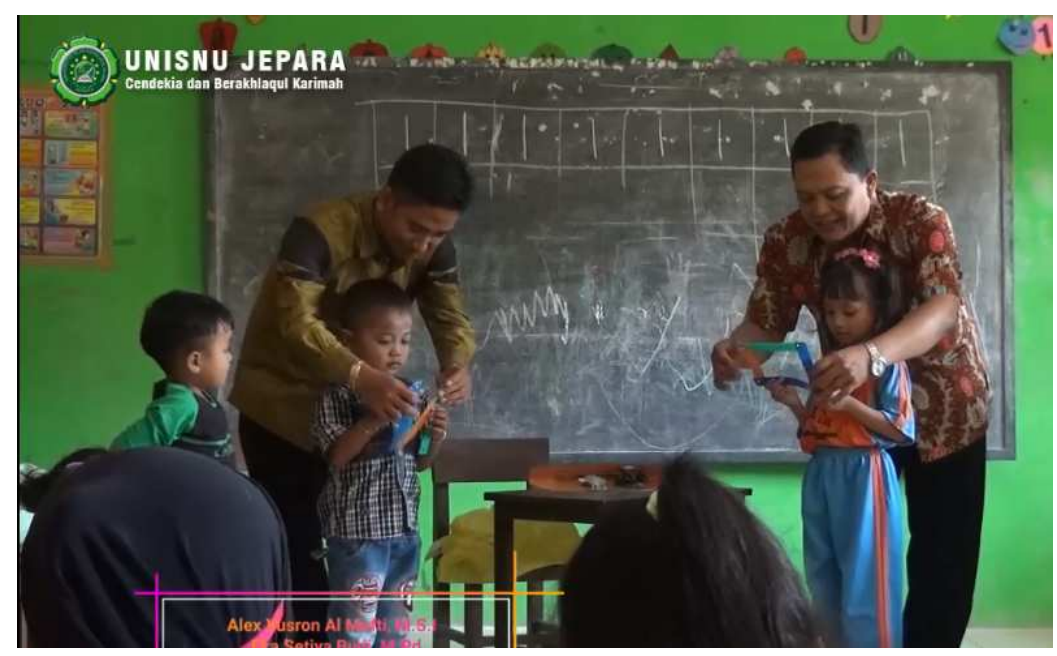

Gambar 7. Praktik menggunakan Stik Pelangi 


\section{KESIMPULAN}

Berdasarkan hasil kegiatan dan pembahasan di atas, pengabdi menyimpulkan bahwa program PKM pembuatan stik pelangi di TK Pertiwi Desa Bungu adalah baik. Hal ini terbukti dengan dapat berjalannya program sesuai dengan harapan. Dengan stik pelangi ini pembelajaran menjadi lebih efektif dan efisien serta dapat bermakna bagi peserta didik.

\section{UCAPAN TERIMA KASIH}

Ucapan terima kasih juga kami sampaikan kepada mitra pengabdaian dan semua pihak yang telah membantu terlaksanaanya pengabdian ini, antara lain:

1. Kepala TK Pertiwi Desa Bungu

2. Dewan Guru TK Pertiwi Desa Bungu

3. Unisnu Jepara

4. Petinggi Desa Bungu

\section{DAFTAR PUSTAKA}

Brewer, A.J. (2007). Introduction to Early Children Education Pre School throughPrimary Grades. Pearson Allin \& Bacon

Budi, E.S. (2017). "Pengembangan Kipas Pintar Untuk Pembelajaran WADAH (Warna, Angka, Bangun Datar, alfabeth, dan Huruf Hijaiyah" Jurnal Transformatika volume 1 nomor 2 tahun 2017, Magelang: Untidar

Campagne, D.M. (2007). Commonly Known As the Premenstrual Syndrome, Still Lacks Defined and Validated Contents . European Journal of Obstetrics.

Darmadi. 2017. Pengembangan Model Metode Pembelajaran dalam Dinamika Belajar Siswa. Yogyakarta: Deepublish

Koesoema, D.A. (2007). Pendidikan Karakter: Strategi Mendidik Anak di Zaman Global. Jakarta: Grasindo. Cet. I

Marilyne, F. \& Sue, D. (2009). Play an Pedagogy in Early Childhood Bending the Rules. Harcourt: Sydney, Forth Wotrh, Lpndon, Sandiego, Toronto

Senjaya, W. 2008. Strategi Pembelajaran; Berorientasi Standar Proses Pendidikan. Jakarta: Kencana Prenada Media Group

Setiawan. (2000). Lingkaran. Yogyakarta. PPPG Matematika

Sugiyono. (2009). Memahami Penelitian Kualitatif. Bandung: Alfabeta.

Suharjana, A. (2008). Pengenalan Bangun Datar dan Sifat-sifatnya di SD. Jakarta: Pusat Pengembangan dan Pemberdayaan Pendidik dan Tenaga Kependidikan Matematika

Sumiati \& Asra. (2009). Metode Pembelajaran. Bandung: CV Wacana Prima

Winataputra, U. S. (2003). Strategi Belajar Mengajar. Jakarta: Pusat Penerbitan Universitas Terbuka

Zuchdi, D. dkk. (2009). Pendidikan Karakter: Grand Design dan Nilai-nilai Target. Yogyakarta: UNY Press. Cet. I. 